\title{
Teoria Crítica Feminista em tempos de capitalismo financeirizado
}

Critical Feminist Theory in Times of Financial Capitalism

\author{
Mariana Prandini Assis' (iD) 0000-0002-5566-2613 \\ Cristiano Rodrigues ${ }^{2}$ (D) 0000-0002-3950-0032 \\ Darlane Silva Vieira Andrade ${ }^{3}$ (iD) 0000-0003-2252-1897
}

'Universidade Dalhousie, Halifax, Faculdade de Direito, Nova Scotia, Canadá. B3K 1P3 - lawinfo@dal.ca

${ }^{2}$ Universidade Federal de Minas Gerais, Faculdade de Filosofia e Ciências Humanas, Departamento de Ciência Política, Programa de Pós-Graduação em Ciência Políica,

Belo Horizonte, MG, Brasil. 31270-901

${ }^{3}$ Universidade Federal da Bahia, Salvador, BA, Brasil. 40210-730-degf@ufba.br/gadneim@ufba.br

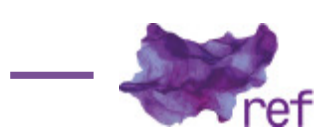

Nancy Fraser é uma filósofa norte-americana, professora de Filosofia e Política da New School for Social Research em Nova lorque. Considerada um dos nomes mais importantes da teoria crítica e do pensamento político feminista, a trajetória de Nancy Fraser é caracterizada por um diálogo contínuo com alguns dos mais destacados pensadores políticos do século XX, entre eles Jurgen Habermas, Iris Young, Seyla Benhabib, Richard Rorty, Michel Foucault, Jacques Derrida, Drucilla Cornell, Judith Butler, Axel Honneth e Rahel Jaeggi. Outro traço marcante de sua longeva e profícua carreira é a centralidade da Teoria Crítica (FRASER, 1997) e de seu firme posicionamento a favor da construção de alternativas ao capitalismo (FRASER, 2013). Em vários momentos de sua carreira, Nancy Fraser trouxe a teoria crítica para dialogar com as questões mais prementes do período. Por essa razão, em alguns momentos o feminismo socialista veio para o primeiro plano, depois a teoria da justiça e sua análise da dimensão normativa da teoria social crítica. O mesmo ocorreu em sua análise sobre a relação entre redistribuição, reconhecimento e representação, a proposição de estratégias políticas para mitigar formas de exclusão. Mais recentemente, Fraser tem se dedicado à luta em defesa do meio ambiente e contra a expansão predatória do capitalismo financeirizado sobre as dimensões políticas e sociais do tempo presente, o que, em última instância, fomenta a deterioração progressiva da democracia. Nos encontramos com Nancy Fraser em 2017, quando a filósofa completava 70 anos, a maior parte desse tempo dedicada ao desenvolvimento de uma teoria crítica capaz de responder às questões sociais e políticas mais urgentes de seu tempo. Nesta entrevista, a autora nos fala sobre os principais elementos dessa teoria, a trajetória que a levou à academia, a importância do diálogo acadêmico e o seu atual projeto de investigação sobre a crise que vivemos. 
E - Gostaríamos de começar pedindo para que você fale sobre sua trajetória acadêmica e intelectual, que se iniciou com seu engajamento com a segunda onda do feminismo e, em seguida, moveu-se para a teoria crítica e um diálogo profundo com as obras de Jürgen Habermas e Axel Honneth.

Nancy Fraser - Eu acredito que a orientação subjacente ao meu trabalho não mudou desde o início, mas houve diferentes focos que vieram para o primeiro plano em diferentes momentos. Eu diria que o que é absolutamente consistente em toda minha carreira é minha percepção de mim mesma como uma teórica crítica. E isso tem duas fontes. Primeiramente, veio das minhas experiências na Nova Esquerda antes que eu entrasse na pós-graduação, quando eu ainda era uma adolescente em Baltimore, minha cidade natal, que era uma cidade segregada pelo Jim Crow. Eu me envolvi na luta pela (des)segregação, ainda no ensino médio, e no movimento contra a guerra no Vietnã. E depois, quando eu estava na graduação, estudando Filosofia, eu passei, ao mesmo tempo, a me envolver no movimento estudantil e em um tipo de marxismo (semitrotskista, mas uma forma não doutrinária do trotskismo) dentro da Nova Esquerda. E quando me formei, em 1969, eu não fui imediatamente para a pós-graduação. Eu permaneci fora por cinco anos, fazendo ativismo político, e durante esse período também participei de grupos de estudo, lendo Marx, Marcuse, pensamento feminista (na medida em que se tinha um, naquela época), todos do ponto de vista da teoria crítica com uma mirada para a transformação social.

Em um certo momento, na década de 1970, tornou-se claro para mim que a Nova Esquerda estava perdendo força e até mesmo caindo aos pedaços e que eu precisaria de algum tipo de plano de longo prazo de desenvolvimento intelectual. Foi quando, em 1975, voltei à universidade para fazer o doutorado em filosofia. Portanto, são realmente cinco anos e meio, ou seis, de hiato. $\mathrm{E}$ quando eu comecei meus estudos de doutoramento, eu já tinha uma visão de mundo completamente formada. Eu não era alguém que chegou lá e que iria ser transformada em um determinado tipo de produto. Sempre estive vinculada a esse modelo de teoria crítica, de característica muito interdisciplinar - ainda que eu estivesse na filosofia, eu fazia cursos na história, sociologia, ciência crítica -, que visa à compreensão de uma forma histórica e crítica do desenvolvimento da sociedade moderna, as formas de injustiça e de repressão que foram se integrando estruturalmente. E essa perspectiva informou minha tese de doutorado e assim por diante. Então, eu terminei meu doutorado em 1980, e comecei a fazer o meu trabalho, minhas pesquisas.

Uma coisa que teve início ainda na pós-graduação foi o meu encontro com Foucault. Isso foi algo absolutamente novo, emocionante e muito inspirador, mas também intrigante. Assim, meus primeiros trabalhos tratavam de interrogar este novo modelo de pensamento crítico engajado, que não se encaixava na teoria crítica da Escola de Frankfurt. Eu estava tentando interrogar as propostas foucaultianas do ponto de vista da minha perspectiva já estabelecida, uma perspectiva quase marxista, quase frankfurtiana, democrático-socialista e feminista. E, ao mesmo tempo, outra figura muito importante que surgiu para mim nesse período inicial foi Richard Rorty, porque eu estava lutando e sofrendo no mundo da filosofia analítica dos Estados Unidos. E Rorty surgiu no cenário como um provocador, como com um coquetel Molotov, explodindo tudo, mas a partir de dentro e como alguém que teve que ser levado a sério nesse lugar. E ele abriu o espaço que tornou possível para mim e para muitas filósofas e filósofos jovens nos sentirmos confiantes de que não tínhamos que seguir uma abordagem rígida e que poderíamos fazer outras coisas.

Então, eu estava nessa fase, uma espécie de batalha/diálogo travada em quatro eixos, que envolvia Habermas, que eu havia começado a ler e levar muito a sério, Foucault e outros pósestruturalistas (um pouco de Derrida e assim por diante, mas especialmente Foucault), pragmatismo (o pragmatismo de Rorty), e feminismo. Esses eram os quatro eixos que eu sempre tentei negociar, às vezes criticando um a partir do ponto de vista do outro e vice-versa. O meu primeiro livro, Unruly Practices, tinha críticas a Foucault, Derrida, Habermas, e, em alguns ensaios, eu tentei desenvolver a minha própria alternativa para aqueles pensadores. Mas, ao chamar o livro de Práticas indisciplinadas: Poder, discurso e gênero na teoria social contemporânea (Unruly Practices: Power, Discourse and Gender), eu já partia dessa ideia de que a crítica ao capitalismo era o maior quadro para tudo isso.

Depois, conforme minha carreira foi se desenvolvendo, houve períodos em que a perspectiva feminista ganhou centralidade, mas nunca foi o feminismo liberal ou o feminismo radical, no sentido de Catharine MacKinnon ou Dworkin Andrea Dworkin. Sempre foi uma espécie de feminismo socialista, como nos referíamos a ele então, mas eu diria que era ainda mais que isso: era sempre um feminismo teórico-crítico.

E em outro período a teoria da justiça veio a lume. Eu estava realmente interessada em pensar sobre a dimensão normativa da teoria social crítica, mas nunca gostei da ideia de uma teoria normativa independente ou solta. Eu sempre pensei que a teoria normativa devia estar conectada à crítica da sociedade, ao diagnóstico do tempo presente, à compreensão das bases estruturais profundas da opressão e injustiça social. Quero dizer que, em certo sentido, todo o meu debate, 
quando desenvolvi o modelo de reconhecimento e redistribuição - embora muitas pessoas tenham tomado isso como uma teoria normativa da justiça - foi também uma intervenção política para criticar a unilateralidade da virada cultural nos Estados Unidos e sua negligência quanto à economia política. E eu sempre pensei nisso como um projeto em três níveis. Havia a dimensão normativa, mas também a dimensão teórico-social, que eu compreendia como sendo a relação entre má distribuição e falso reconhecimento em uma sociedade capitalista. Eu buscava analisar esses aspectos para entender a relação entre desigualdade de classe e desigualdade de status. E o terceiro nível era, digamos, o nível político, para entender as lutas sociais e o tipo de orientação estratégica dos movimentos sociais de modo a intervir proveitosamente nesta situação socioestrutural historicamente específica que tinha pelo menos estas duas dimensões. Depois, agreguei uma terceira dimensão: a representação. E todo o meu debate com Axel Honneth foi tanto sobre teoria social e política quanto sobre como entender o capitalismo, como se ele fosse apenas uma nuance da teoria.

Eu sinto que há uma orientação subjacente consistente ao longo de todas essas fases da minha carreira, e agora, pelo menos neste momento inicial de meu novo projeto, desloco a dimensão normativa um pouco para o fundo e foco mais na dimensão estrutural. Especialmente para compreender a presente forma do capitalismo, que é bastante diferente da forma de capitalismo que existia no início da minha trajetória. Nos primeiros estágios da minha carreira, eu criticava as formas de injustiça, a cegueira de gênero, racismo, e assim por diante, que foram construídas dentro de um capitalismo social-democrático gerenciado pelo estado. Agora eu estou tentando compreender as formas de injustiça que estão minando a democracia e a sustentabilidade ecológica, entre outras coisas, em um novo tipo de capitalismo. Para este momento, esta tentativa de mapear a totalidade social no espírito da teoria crítica aparece em primeiro plano em relação aos aspectos normativos, mas não estou me esquecendo deles e, numa fase posterior, eu os trarei mais para o centro.

Para mim, eu não sei como isso é visto de fora, mas, a partir de dentro, eu sinto que há um compromisso consistente subjacente com a teoria crítica, no sentido em que a entendo, a partir de diferentes focos em diferentes momentos. Isso tem a ver, em parte, com alterações na situação histórica, e, em parte, com a mudança de desenvolvimentos políticos e dos movimentos sociais nos quais eu sinto necessidade de intervir.

E - Seu trabalho é caracterizado por um diálogo frutífero com outro/as intelectuais crítico/as e outros campos teóricos. Destacamos seu engajamento com os trabalhos de Iris Marion Young, Judith Butler, Honneth e Habermas, por exemplo. O quão importante são essas conexões e diálogos para o desenvolvimento de suas perspectivas teóricas?

Nancy Fraser - Vocês estão certas sobre esta questão do diálogo ser muito constante e importante durante toda a minha carreira. $\mathrm{E}$, como acabei de dizer, em resposta à sua primeira pergunta, desde o início da minha carreira eu já me construía algum tipo de diálogo, ainda que apenas dentro da minha própria cabeça, entre esses quatro polos: o pós-estruturalismo foucaultiano, a teoria crítica habermasiana, o pragmatismo rortyniano e as várias formas de feminismo que eu fui encontrando. Mas, ainda que eu estivesse em diálogo com eles, mesmo que em alguns casos ninguém estivesse me respondendo - Habermas nunca respondeu à minha crítica feminista, Foucault nunca respondeu diretamente às minhas críticas, embora eu saiba que ambos tiveram conhecimento delas, e não ficaram exatamente felizes com elas -, mas depois eu acabei encontrando pessoas com as quais eu pude estabelecer conversas recíprocas.

Uma das primeiras experiências dessa natureza foi Der Streit urn Differenz, publicado como Feminist Contentions em inglês, com Seyla Benhabib e Judith Butler, e mais tarde Drucilla Cornell. Naquele trabalho estávamos precisamente argumentando sobre quais seriam os usos, para a teoria feminista, da teoria crítica alemã, de um lado, e do pós-estruturalismo francês, de outro, com Butler defendendo o estruturalismo, Benhabib defendendo a teoria críica habermasiana, e eu, como sempre, tentando falar de ambos, não a partir de um ecletismo simplório, mas os colocando juntos de tal maneira que poderia superar as fraquezas e os pontos cegos de cada um e utilizar seus pontos fortes, usando uma perspectiva para corrigir os pontos cegos da outra.

E então o trabalho Redistribution or Recognition? se provou bastante frutífero para o diálogo e foi, de fato, desenvolvido em grande parte por meio de diálogos, pois havia, sim, algumas trocas com Iris Young por um lado, e com Judith Butler por outro e, em seguida, com Richard Rorty. Tudo isso foi publicado no livro Adding Insult to Injury, bem como, em seguida, escrevi um livro com Axel Honneth sobre o mesmo tema. Em todos esses casos, eu tive que responder às críticas provenientes dessas grandes e brilhantes pensadoras e pensadores. Isso me levou a desenvolver o meu próprio pensamento de uma maneira muito mais forte e profunda do que eu poderia ter sido capaz de fazer sozinha. Quando você está trabalhando a partir de uma perspectiva na qual você está inserida, de certa forma, no interior dela nem sempre vê quais são seus pontos cegos. Mas quando outras pessoas, que realmente entendem o que você faz de uma maneira profunda, levantam objeções ou críticas e 
essas objeções e críticas são sérias, pertinentes e não apenas críticas vazias, que você pode simplesmente dizer 'deixa pra lá, eles não sabem o que estou fazendo'; este é o melhor presente que qualquer um pode lhe dar, porque as críticas a impulsionam e a inspiram a aprofundar seu pensamento. E eu me beneficiei tremendamente de todos esses intercâmbios, também com Rainer Forst, e todos os outros e outras que contribuíram para aquele volume.

Atualmente, eu estou envolvida em outro projeto de diálogo, semelhante àquele. Estou escrevendo um livro com Rahel Jaeggi (Rahel Jaeggi/Nancy Fraser, Capitalism - A Conversation in Critical Theory, Cambridge, Polity Press, 2018), que é uma professora de Filosofia na Universidade Humboldt, em Berlim, e ele terá a forma de conversações ou diálogos. Não é como o trabalho com Honneth, em que cada um de nós escreveu cada capítulo separadamente e, em seguida, os aglutinou. Este é uma conversa verdadeira que planejamos juntas, gravamos, transcrevemos e editamos. Portanto, é um monte de idas e vindas que está se provando extremamente frutífero e interessante.

E - Os seus trabalhos sobre teoria do reconhecimento (especialmente o texto "Da redistribuição ao reconhecimento") são muito influentes no Brasil, tendo servido de base para um grande número de teses e artigos científicos. Ao longo dos anos, você reformulou sua proposta teórica, partindo de uma perspectiva bidimensional (redistribuição e reconhecimento) para uma tridimensional (reconhecimento, redistribuição e representação). Em vários dos seus textos há uma crítica, por vezes implícita e por outras explícita, às políticas de identidade. Como você vê a relação entre políticas de identidade e reconhecimento? São a mesma coisa? Qual o seu potencial emancipatório em um contexto de extrema privação material e crescente desigualdade, como vivemos hoje?

Nancy Fraser - Em primeiro lugar, eu gostaria de detalhar melhor o que quero dizer quando falo de política de identidade e por que sou cética em relação a ela. Eu diria que toda política, todo movimento social, produz e pressupõe uma certa construção acerca de sua própria identidade. Eu penso que isso é verdadeiro para o movimento operário, para os movimentos socialistas, para todos os tipos de movimentos sociais - eles necessariamente constroem, pressupõem e carregam consigo algum tipo de modelo, algum tipo de ideia sobre quem é o sujeito do movimento. Isso se passa no terreno dos movimentos e das lutas sociais. E não pode ser evitado. Não é isso que considero como sendo política de identidade.

Para mim, política de identidade é quando um movimento social toma a sua identidade como o foco da sua atividade, não apenas algo que se constrói ao mesmo tempo em que se faz outras coisas. E mesmo naquela primeira acepção, em que os movimentos sociais inevitavelmente pressupõem e constroem suas próprias identidades, pode haver vários tipos de aspectos problemáticos. Por exemplo, em muitas situações, em muitos países, em muitos períodos, movimentos de trabalhadores têm, sem mesmo perceber ou querer fazê-lo, construído a imagem do sujeito do movimento operário como sendo o homem branco ou o trabalhador fabril da nacionalidade majoritária de uma maneira que acaba implicando exclusões. Neste caso, teria sido bom se houvesse uma prática do movimento social que fosse reflexiva e crítica acerca de sua própria abordagem para a construção de uma identidade. E penso que nós poderíamos até mesmo descrever a trajetória dos movimentos feministas em determinados períodos da segunda onda como desenvolvendo essa consciência crítica da própria identidade que o movimento estava construindo.

Tudo isso é útil, de certa forma inevitável e não especialmente problemático. O problema emerge quando a questão da identidade de um movimento, e o reconhecimento ou o não reconhecimento recebido na sociedade como um todo, se torna o foco principal da sua atividade e da sua política, ou seja, quando a luta é uma luta pelo reconhecimento da identidade. Penso que isso é bastante problemático porque, independentemente da identidade que está sendo construída, isso implica a separação de certos elementos que são tornados centrais, empurrando os outros para o fundo. Muitas vezes, isso carrega uma certa força prescritiva: isto é o que realmente significa ser uma mulher, ser uma pessoa negra, gay, lésbica ou uma pessoa trans. Isto é o que você deveria ser se você está reivindicando isso e se você divergir desta identidade prescritiva então há algo de errado com você. Por isso, essa identidade pode desenvolver-se de maneira autoritária e pode facilmente se tornar essencializada. E eu chamei isso, em algum ponto, de o problema da reificação, que está relacionado ao excesso de foco na política de identidade.

O segundo problema é o que eu chamo de deslocamento, ou seja, o deslocamento de outras dimensões importantes de injustiça e opressão. Então, para mim, obviamente, um desses deslocamentos diz respeito aos aspectos político-econômicos da injustiça que, por uma questão histórica, deixaram de ser considerados na medida em que o foco neste tipo de política de identidade, reconhecimento da identidade, tornou-se cada vez mais saliente, pelo menos na América do Norte. Quanto maior o foco na identidade, menor o foco na economia política.

Tendo dito tudo isso, eu penso que não devemos jogar fora o bebê junto com a água do banho, já que há algo correto e importante na política de reconhecimento, se a compreendermos de uma maneira não identitária. Você não pode reduzir todas as injustiças e todas as lutas sociais ao 
âmbito da economia política. Por mais importante que este aspecto seja, as nossas sociedades são ainda mais complexas. Nem tudo pode ser reduzido de volta a essa dimensão. E quando você tem certo tipo de marxismo economicista vulgar que tenta fazer isso, ele acaba excluindo enormes áreas de injustiça e de luta social.

O que eu estava tentando fazer era encontrar uma compreensão não identitária da política de reconhecimento que seria menos suscetível a esses problemas de reificação ou essencialização de um lado, e de deslocamento por outro. Ou seja, uma política de reconhecimento que teria maior capacidade para se articular com lutas materiais, lutas contra a injustiça e a desigualdade socioeconômica, e foi aí que eu desenvolvi a ideia de pensar em reconhecimento como uma questão de status, em vez de uma questão de identidade. E, de fato, eu retomei Max Weber para isso, para a ideia de que há basicamente duas formas bastante diferentes de se entender estratificação social: um modelo de classe e um modelo de status. E Marx e Engels por vezes sugerem, como, por exemplo, em O Manifesto Comunista, que o triunfo do capitalismo estaria justamente em apagar todas estas formas de desigualdade de status: os trabalhadores não terão pátria, todo nacionalismo irá desaparecer, o racismo irá desaparecer, tudo poderia ser moído para baixo nesta massa indiferenciada, trabalhadores internacionais que se uniriam.

Essa proposta mostrou-se obviamente errada, hierarquia de status, desigualdade e injustiça de stałus continuam a existir no capitalismo. Na verdade, talvez seja errado dizer "continuam a existir". O capitalismo cria novas formas. Não é apenas uma ressaca dos tempos pré-capitalistas. Então, eu estava pensando em como poderíamos compreender a imbricação entre status e classe em nossa sociedade. E usei o modelo de status para dar uma interpretação alternativa à política de reconhecimento, em seu melhor formato. E esta proposta ia em duas direções. Uma era dizer às pessoas envolvidas na política de identidade: "a sua questão é séria, mas há uma maneira melhor de lidar com ela. Não, a dimensão identitária não deveria estar muito em primeiro plano". Ao mesmo tempo, era uma maneira de dizer a alguns social democratas, republicanos e outras pessoas que querem simplesmente rejeitar tudo isso e dizer "vamos voltar para a classe, a coisa real", é uma proposta a eles: "Aqui está uma maneira de entender como as questões levantadas por esses novos movimentos sociais podem se articular com questões de classe, aprofundá-las, enriquecê-las e complicá-las. Não há necessidade de deslocá-las". Portanto, esta foi, em grande parte, uma proposta para tentar criar relações frutíferas e diálogos entre a chamada esquerda social e a chamada esquerda cultural.

E - Em "Falsas antíteses", um diálogo com Seyla Benhabib e Judith Butler, você aponta a possibilidade de síntese entre elementos da "teoria crítica" e do "pós-estruturalismo". Muitos anos se passaram desde esse texto e, ao menos no contexto brasileiro, o pós-estruturalismo se transformou em um paradigma bastante influente, ao mesmo tempo em que é alvo de muitas críticas por não atentar às dimensões estruturais das relações de poder. Você ainda pensa ser possível tal síntese? E quais seriam as bases dela?

Nancy Fraser - Sim, e eu acho que é interessante, em primeiro lugar, ouvir vocês descreverem a situação brasileira como aquela em que a influência do pós-estruturalismo está aumentando. Minha impressão é de que nos Estados Unidos essa influência está, na verdade, diminuindo. Eu acho que as coisas chegaram a um certo ponto em que não se tem mais todo esse entusiasmo em torno de Jacques Derrida ou Jacques Lacan. Tem havido um certo abalo. Michel Foucault é a pessoa, e eu sempre suspeitei que este seria o caso, que permanece importante e influente. $\mathrm{E}$ embora eu fosse um tanto cética no início em relação ao paradigma da governamentalidade, eu tenho visto estudiosos foucaultianos realizando trabalhos que são muito interessantes e potencialmente muito úteis sobre subjetivação neoliberal e sobre racionalidade política neoliberal. Gostaria de citar, por exemplo, o livro da Wendy Brown, Undoing the Demos.

Eu acredito que o paradigma foucaultiano está se tornando mais rico e útil do que poderíamos ter previsto anteriormente, e na palestra que dei na noite passada, infelizmente, eu cortei essa parte por causa do tempo, mas no texto escrito existem muitas passagens em que me baseio nesta crítica da governamentalidade e tento integrá-la ao tipo de crítica estrutural que estou desenvolvendo em termos das condições subjacentes para a possibilidade da economia capitalista.

Bem, podemos dizer que todo o modelo de subjetivação, que eu associo a Foucault, pode ser pensando em muitos e diferentes níveis. Em um nível, penso que podemos olhar para os elementos de reprodução social, que têm a ver com as práticas que produzem e socializam os sujeitos humanos do capitalismo. Esse é um lugar onde eu acredito que poderíamos fazer algumas conexões entre as ideias foucaultianas de subjetivação e, mais uma vez, é este tipo de crítica feminista semimarxista que eu venho tentando desenvolver. Também no nível das questões de cultura política, hegemonia e contra-hegemonia, para entender como o neoliberalismo tem hegemonizado formas de pensar e de subjetivação que antes pareciam críticas, incluindo o feminismo liberal e outras correntes liberais de novos movimentos sociais. Neste nível, eu estou lendo, por meio de uma lente gramsciana, que suponho tenha algo a ver com Chantal Mouffe e Ernesto Laclau, mas, ao contrário 
deles, eu não acho que tudo é discurso e que a estrutura é de alguma forma evacuada pelo discurso. Então, sim, acredito que agora seja um bom momento para tentar relacionar uma perspectiva que você poderia chamar de neomarxista, com elementos de Habermas, elementos de Govanni Arrighi, elementos de algum tipo de feminismo, para conectar tudo isso com uma certa linha de pensamento foucaultiano. Para mim, este é um bom momento para o desenvolvimento desta integração.

E - Isso que você acabou de dizer faz uma boa conexão com a nossa próxima pergunta, que é sobre movimentos sociais, especialmente os movimentos sociais atuais, como o Ocupa Wall Street, e a onda emergente de manifestação global. Qual a sua opinião sobre isso?

Nancy Fraser - Essa sim é uma boa conexão. Então, eu pensaria acerca disso a partir de dois ângulos diferentes. Para mim, a coisa mais importante é ajudar a criar uma compreensão sobre a inadequação dessa orientação neoanarquista entre os jovens. Foi muito interessante visitar a comunidade de Dandara' ontem e ver como as pessoas que estão realmente tentando construir alternativas não são, de modo algum, completamente suscetíveis a esse anarquismo romântico. Elas precisam organizar uma forma de viverem juntas, tomar decisões, coordenar, defender e se proteger contra a política e as forças do Estado que basicamente querem destruí-las. Então, a primeira coisa é que esse neoanarquismo vem de uma localização social privilegiada. A segunda, eu diria que a história de um movimento como o "Ocupa Wall Street" é muito instrutiva. Que esse movimento tenha tido um enorme potencial e tenha sido capaz de capturar tanto a atenção pública e ganhar tanto apoio público nos Estados Unidos, e penso que isso também foi verdadeiro para movimentos análogos em outros lugares, é algo incrível. Mas é também entristecedor que essa maravilhosa oportunidade tenha, de algum modo, sido perdida ou desperdiçada por causa dessa grande ênfase no processo, em intermináveis assembleias gerais que duravam horas a fio para decidir uma coisa simples. Quem - ou quais estudantes - tem tempo para isso? Pessoas comuns que necessitam cuidar de seus filhos, que precisam trabalhar, que têm que ganhar suas vidas não podem fazer isso. Essa abordagem trouxe certas vozes para o centro. Isso é irônico: o movimento deveria ser inclusivo, mas por causa de sua subjacente economia-política e sociologia, o movimento se tornou excludente, e não deixa absolutamente nada para trás. Ele desapareceu praticamente sem rastros. E é essa abordagem que eu considero profundamente problemática e eu gostaria de conquistar aqueles jovens anarquistas que têm tanta energia e cujos corações estão no lugar certo, convencendo-os a encontrarem uma orientação política diferente.

O segundo ponto diz respeito à possibilidade de afinidade entre algumas das orientações subjetivas que vêm desses movimentos e a subjetivação neoliberal. E vocês estão certos em dizer que Boltanski e Chiapello são os pioneiros aqui. Eles mostraram como o neoliberalismo foi capaz de fazer uso de energias que, à primeira vista, pareciam se opor completamente a isso, ou ao menos serem fortemente anticapitalistas. Eles focaram no que chamo de crítica artística do capitalismo, vinda da Nova Esquerda. A crítica da burocracia, a crítica da conformidade, a crítica das organizações de larga escala, e a valorização da iniciativa individual, da imaginação, do 'faça-você-mesmo', das redes, tudo isso. Eles mostraram como aquilo foi traduzido em uma nova forma de orientação econômica.

Richard Sennett escreveu um livro muito interessante [The New Culture of Capitalism] que traz uma espécie de crítica paralela. Ele parece ser um pouco otimista demais sobre o tipo de mundo social-democrático que eu acho que todos devemos tentar criticar. Mas, ainda assim, Sennett mostra como a crítica à burocracia, vinda da Nova Esquerda e dos novos movimentos sociais, meio que se amalgamou a uma certa crítica da direita acerca do Estado e eventualmente com um tipo de ideia que defende que redes e mercados se constituem em formas melhores de organizar as coisas do que as estruturas estatais ou políticas.

Eu mencionaria ainda o trabalho de Blair Taylor, que escreveu uma tese extremamente interessante na New School, analisando toda a história da Nova Esquerda, especialmente a norte-americana, de Seattle até Occupy, precisamente nesses termos, ou seja, como contribuindo para criar um novo espírito de radicalismo político que é muito convergente com a subjetivação neoliberal. Eu acredito que essa tese, que eu espero se torne um livro, discutirá esse caso em maiores detalhes do que eu poderia fazer. Ele é um profundo conhecedor da história desses movimentos.

E - Em seus trabalhos recentes, você tem sido bastante crítica a uma forma dominante dentro do feminismo que tem sido utilizada para se alinhar ao neoliberalismo. Você acredita que ainda há espaço para a crítica feminista na política contemporânea?

Nancy Fraser - Bem, primeiramente, há espaço para uma crítica feminista. Vivemos em um mundo completamente sexista e androcêntrico. Eu diria que, se o capitalismo regulado pelo estado foi construído a partir do ideal do salário-família em que o homem ganharia o pão e as

\footnotetext{
' Dandara é uma ocupação urbana ainda não regularizada na região da Pampulha, em Belo Horizonte, na qual vivem
} aproximadamente 1.800 famílias. 
mulheres seriam donas de casa e mães, e isso foi uma problemática sexista ideal, a forma atual do capitalismo é construída com base na ideia de que todo mundo tem que ser um trabalhador assalariado e doar todo seu tempo para atividades sociorreprodutivas necessárias à sociedade. E este é um mundo em que, de alguma forma, pede-se às mulheres que sejam como os homens sem, de modo algum, prover qualquer alternativa para se organizar, o que era, historicamente, a responsabilidade das mulheres pela reprodução social. E, na verdade, ainda é responsabilidade, principalmente das mulheres. Do meu ponto de vista, toda a organização contemporânea do capitalismo neoliberal financeirizado é baseada em uma ordem de gênero bastante problemática. Trata-se de uma nova ordem de gênero, a família com dois provedores, em vez do modelo do salário-família, mas completamente androcêntrica. É um modelo que estabelece profundas hierarquias de gênero, sexismo e androcentrismo. Na minha opinião, não há como você entender o capitalismo a partir da perspectiva de uma teoria crítica cega para as questões de gênero. Você pode apenas entendê-lo se você tem uma dimensão feminista da teoria crítica. Não há virtualmente qualquer problema em que uma perspectiva feminista não seja necessária. Mas isso não significa que toda questão seja simplesmente uma questão unidimensional de gênero, e na medida em que alguns movimentos feministas ainda pensam nesses termos, em que o gênero é a única lente por meio da qual eles estão olhando, então esse olhar naturaliza toda uma gama de eixos de dominação e subordinação, despolitizando-os, tornando-os invisíveis, o que acaba beneficiando uma fina camada de mulheres altamente privilegiadas às expensas de todas as outras.

Então sim, há a necessidade de uma perspectiva de gênero, mas tem que ser o tipo certo de perspectiva de gênero e que, em minha opinião, extrai e é informada por uma imagem ampliada, estruturalmente matizada, de como se parece a nossa sociedade, de onde origina a hierarquia de gênero, como ela se baseia na ordem social, e como ela se intercepta com uma estrutura de classes, com uma ordem étnico-racial hierárquica e com desequilíbrios nacionais, e assim por diante.

E - E em relação às feministas do Sul Global? Você vê alguma conexão entre seu trabalho e os delas? Alguma feminista do Sul Global exerce ou exerceu alguma influência em seu trabalho?

Nancy Fraser - Bem, a minha suspeita é que é provável, e talvez já esteja acontecendo precisamente no Sul Global, que o feminismo vá se desenvolver de uma forma que realmente reflita os tipos de preocupações que eu acabei de apresentar. Quero dizer, eu não sou tão conhecedora quanto eu gostaria de ser acerca do feminismo de várias regiões no Sul Global, o que é dificultado em parte por minhas habilidades de linguagem e assim por diante.

Mas é óbvio que, em contextos onde a luta por subsistência e para sustentar uma família e uma comunidade e um mundo da vida, onde essa luta é tão intensa e tão premente, é lógico que você não vai ter o tipo do feminismo lean in [referência ao livro de Sheryl Sandberg - o feminismo advogado por ela] que estamos vendo se desenvolver no Norte Global. Então, acredito que haja algo na situação do Sul Global, a gravidade da crise, que deve fazer com que muitas feministas, provavelmente não todas, já estejam abertas, desenvolvendo e pensando em termos como os que estou propondo.

Eu também entendo que os desenvolvimentos atuais estão aumentando a desigualdade no Sul Global e que está se criando um pequeno estrato de mulheres feministas privilegiadas que podem estar produzindo formas de feminismo que não são tão diferentes das hegemônicas no Norte Global. E eu posso imaginar que essas feministas têm acesso a recursos e meios de comunicação para que suas vozes possam ser ampliadas nos próximos anos. Eu não sei. Mas meu senso é que muitas das questões que estão atualmente em minha mente são muito prementes no Sul Global e que os movimentos sociais em geral no Sul Global são o lócus para o qual eu gostaria de olhar em busca dos desenvolvimentos mais interessantes. $\mathrm{E}$, claro, quero apoiar fortemente a sua ideia da importância desta comunicação transnacional e, possivelmente, da coordenação.

E - Temos ouvido de muitas pessoas, e você mesma tem observado isso, que, na América Latina, após a chamada onda rosa, tem havido um grande e grave retrocesso com o ressurgimento de uma direita extremista, até mesmo fascista. Será que você poderia falar um pouco sobre isso, como você vê a esquerda no mundo contemporâneo e quais são as perspectivas de futuro para ela? Nancy Fraser - Bem, eu acho que a situação da esquerda hoje é muito paradoxal, vamos falar globalmente em primeiro lugar. O paradoxo é que realmente há uma crise muito aguda de sistema, uma crise multidimensional que envolve um aspecto ecológico realmente terrível, bem como este aperto muito severo na reprodução social de que falamos e uma espécie de crise política em que a neoliberalização está desfazendo todas as formas políticas que poderiam, em teoria, resolver os problemas sociais, esvaziando assim as instituições políticas.

Então, a crise econômica, a crise financeira, a crise política, a crise social, a crise ecológica, é alucinante e você esperaria, em teoria, que a reação a isso seria uma politização muito forte, nem toda a partir da esquerda naturalmente, claro que haveria movimentos fascistas e respostas da direita também, mas o mais perturbador disso tudo é que, no momento, a maior parte da energia 
está com a direita, ao passo que a esquerda se encontra bastante desmoralizada. Há muitas pessoas em diferentes locais no mundo que, de forma explícita ou implícita, pensam sobre essas questões de uma maneira que poderíamos chamar de esquerda, mas elas não têm a confiança, a energia, a esperança que daria origem a uma alternativa real, coordenada e em larga escala. Pessoas de direita têm muito mais confiança de que elas sabem o que fazer sobre isso, o que é assustador, porque as coisas que elas querem fazer são realmente para nos levar totalmente para o inferno. Por que há tanta confiança na direita e não no oposto, na esquerda?

Eu concordo que a situação da América Latina é bastante específica, não sou de modo algum uma especialista nesse assunto, mas me pareceu que, durante uma boa década, essa regiáo foi o tipo de exceção global, o único lugar no mundo em que houve uma resposta vinda da esquerda ou centro-esquerda. Vocês vivenciaram a neoliberalização muito cedo sob a ditadura e provavelmente, para vocês, neoliberalização, repressão, oligarquia e o novo capitalismo estiveram todos ligados e, quando a ditadura acabou, todas essas coisas foram de alguma forma desacreditadas juntas. Vocês tiveram então uma compreensão precoce dos graves problemas trazidos pelo neoliberalismo e os muitos, muitos momentos positivos, momentos esperançosos que a abertura democrática trouxe. Eu suponho que as pessoas tivessem então a confiança necessária para construir um novo mundo e se oporem ao neoliberalismo, e então tivemos todas essas vitórias tremendas, vitórias políticas em qualquer caso, vitórias eleitorais de país em país. Podemos falar sobre o que esses regimes fizeram de bom e ruim, as diferenças entre eles e assim por diante, mas, deixando esses detalhes de lado, o contexto maior indicava que este era o único lugar no mundo onde víamos uma resposta política real, uma tentativa, pelo menos em alguns lugares, ou um discurso, visando à criação de uma alternativa à neoliberalização e, em alguns casos, mesmo algumas políticas reais que tentaram fazer isso.

E eu não posso começar a explicar como em muitos, talvez na maioria dos grandes países da América do Sul, isso agora está se esvaindo e se tornando muito tênue, por um fio. Este é certamente o caso da Argentina e daqui. A situação venezuelana é realmente horrenda e, de qualquer forma, em cada país vemos agora um enorme ressurgimento da oposição de direita contra a onda rosa. Vocês conhecem pessoas que entendem a política na região muito melhor do que eu para explicar o porquê. E tem a tragédia da destruição grega do que parecia ser uma aliança real e enorme em torno da oposição Syriza à austeridade e assim por diante. E é preciso dizer que o esforço deliberado da Troika para humilhar a oposição grega, para ensinar ao resto da Europa e do mundo uma lição, é tudo muito desanimador.

Acrescente-se a isso, para entendermos a situação como um todo, o fracasso dos movimentos Ocupa fora da Espanha em encontrar uma maneira de institucionalizar essas energias, a ascensão deste novo anarquismo de que falamos antes, a cooptação de elementos dos novos movimentos sociais no quadro neoliberal, como o feminismo hegemônico e outros. Todas essas situações apresentam um quadro que é bastante perturbador, no qual nós, a partir de um ponto de vista, abre aspas fecha aspas, "racional", precisamos compreender o que isso significa. Significa que há uma crise da esquerda, há uma crise da emancipação, e parece que não temos a capacidade de nos levantar para a ocasião. Temos uma situação histórica e objetiva que exige uma resposta coordenada, séria e de larga escala, e todos os desenvolvimentos que estou descrevendo são totalmente inadequados para isso. Novamente, eu não tenho uma resposta, mas posso dar uma descrição.

E - E, nossa última questão. Você falou um pouco sobre isso, mas acreditamos que as pessoas possam estar muito interessadas em saber mais sobre o seu projeto atual, acerca da crise que estamos vivendo, e você está falando de uma crise multidimensional. Como surgiu esse projeto, quais são as razões por trás dele, e como você o vê se desenvolvendo?

Nancy Fraser - Certo, bem, isso surgiu através da experiência da crise de 2007-2008, o surgimento de Occupy e um sentimento de que, no plano intelectual, os/as teóricos/as críticos/as não estavam realmente abordando o assunto. Acho que uma importante vertente da teoria crítica está muito presa à especialização acadêmica.

Há pessoas especializadas em direito constitucional, ou na teoria dos direitos humanos, ou na teoria normativa independente, mas muito poucas pessoas estavam realmente tentando fazer 0 que Marx fez em seu tempo, ou o que Habermas tentou fazer na década de 1970, ou até mesmo os teóricos críticos mais antigos tentaram fazer em seu tempo, e isso é entender realmente a sociedade como uma totalidade, compreendendo todos os problemas que acompanham essa aspiração, tentando fazer isso, tentando entender o que é construído, as tendências inerentes à crise, voltando à noção de que uma crise é a expressão de verdadeiras contradições e tensões estruturais dentro de uma ordem social, que não é acidental, que essas coisas estão realmente, em certo sentido, objetivamente lá, e por longos períodos são geridas, massageadas e continuam acontecendo, mas que há momentos em que realmente elas entram em erupção.

E eu só queria voltar a essas origens, e obviamente que Marx é o grande pensador aqui. Eu estava frustrada ao ver que os/as teóricos/as crítico/as não estavam fazendo isso, e eu também estava 
frustrada em ver que os/as marxistas estavam fazendo isso da mesma velha maneira que considero inadequada.

Então você tem pessoas que eu admiro e respeito, como David Harvey, que eu acho que é uma pessoa de boa vontade. Ele não é somente um brilhante pensador marxista dentro do marco marxista, o que tem tremendas forças e limitações, mas ele é pessoalmente alguém que quer ser sensível a gênero, a outras dimensões do mundo social e a formas de injustiças que não são imediatamente clarificadas por seu tipo de marxismo. Ele está constantemente fazendo referências a essas dimensões, mas ele não as integra de maneira conceitual e sistemática em seu pensamento. E eu acho que o mesmo é verdade para todos os outros importantes pensadores marxistas com quem eu aprendo muito: Costas Lapavitsas é realmente um dos teóricos mais interessantes da dívida do capital financeiro.

Então, eu decidi que faria disso o meu trabalho, tentar desenvolver uma crítica sobre a crise, um modelo de crise para o presente, que tratasse dos elementos que os marxistas estavam olhando, a economia financeira, como um, abre aspas fecha aspas, "primeiro plano", e então, olhasse para a forma como este primeiro plano dependia de um conjunto de condições que o próprio primeiro plano de acumulação econômica estava ao mesmo tempo desestabilizando.

E minha ideia original era usar Karl Marx, Karl Polanyi e Jürgen Habermas para discutir a crise como três modelos diferentes e olhar para as forças e fraquezas de cada um, os insights e os pontos cegos de cada um. Devo dizer que aprendi algo importante de Polanyi, sobre quem tenho muitas críticas (muito romântico, nostálgico sobre a sociedade, e muito negativo em relação à economia, dentre outras); mas o que aprendi com Polanyi é que a relação entre economia e sua condições subjacentes era em si um importante lócus e motor de crise, que não se podia encarar a crise como um problema interno à economia, o que os marxistas tendiam a fazer. Então, é a queda da taxa de lucro e todo esse tipo de coisas, mas também houve, e essas podem ser verdadeiras contradições, contradições e tendências de crise que têm a ver com o que eu vejo agora como o modo como a economia oficial simultaneamente depende e desestabiliza suas condições básicas de possibilidade.

E assim o trabalho que eu estou fazendo agora envolve tentar teorizar três versões específicas disto. Uma versão de reprodução social, em que gênero é especialmente importante e em que tento olhar para as formas em que a produção econômica se beneficia livremente das atividades sociais reprodutivas e, na forma atual do capitalismo, está também comendo-as e espremendo-as e tornando a reprodução social um importante local e foco de crise, sobre e acima da crise tradicional.

Procuro fazer a mesma coisa para a dimensão políica, isto é, mostrar que a construção capitalista de uma economia aqui e de uma política lá e a divisão entre poder econômico e poder político também faz com que a economia se beneficie livremente do poder público. O capitalismo financeirizado está ingerindo e esvaziando as próprias capacidades públicas das quais ele precisa. Isso me confere uma maneira de olhar para a dimensão política da crise, a chamada crise da democracia.

E a terceira dimensão, que estou apenas começando a trabalhar agora, e é o meu próximo trabalho, é a ecológica. Eu acredito que está ficando cada vez mais evidente para todas as pessoas que esta forma de capitalismo, se não o capitalismo em geral, é totalmente incompatível com uma organização ecologicamente sustentável e nos levará a cair no precipício se continuarmos no mesmo caminho.

E - Muito obrigada!

Nancy Fraser - De nada.

\section{Referências}

FRASER, Nancy. Justice interruptus: critical reflections on the "postsocialist" condition. New York: Routledge, 1997. Disponível em https://www.scielo.br/scielo.php?script=sci_arttext\&pid=S0104026X2007000200002.

FRASER, Nancy. Fortunes of feminism: from state-managed capitalism to neoliberal crisis. Brooklyn, New York: Verso Books, 2013.

Mariana Prandini Assis (mariana.prandini@dal.ca) é doutora em Política pela New School for Social Research e pós-doutoranda em Direito na Dalhousie University.

Cristiano Rodrigues (posdcp@africh.ufmg.br) é doutor em Sociologia pelo Instituto de Estudos Sociais e Políticos da Universidade do Estado do Rio de Janeiro (lesp-UERJ). Professor Adjunto do Departamento de Ciência Política da Universidade Federal de Minas Gerais (UFMG) e do Programa de Pós-Graduação em Ciência Política da UFMG (PPGCP-UFMG). Pesquisador do Grupo de Pesquisa em Democracia e Justiça (Margem), do Núcleo de Estudos e Pesquisas sobre a 
Mulher (Nepem) - ambos vinculados ao PPGCP-UFMG -, e da Rede de Pesquisas em Feminismos e Política.

Darlane Silva Vieira Andrade (darlane.andrade@ufba.br) é professora do Departamento de Estudos de Gênero e Feminismo da Universidade Federal da Bahia (UFBA); Docente no Bacharelado em Estudos de Gênero e Diversidade, e do Programa de Pós-Graduação em Estudos Interdisciplinares sobre Mulheres, Gênero e Feminismo da UFBA; Vice-líder do Grupo de Pesquisa CNPq Gênero, Alteridades e Desigualdades (GAD NEIM/UFBA) e integrante do Grupo de Pesquisa CNPq Gênero e Saúde Mental (UnB).

\section{COMO CITAR ESSE ARTIGO DE ACORDO COM AS NORMAS DA REVISTA}

ASSIS, Mariana Prandini; RODRIGUES, Cristiano; ANDRADE, Darlene Silva Vieira. "Teoria Crítica Feminista em Tempos de Capitalismo Financeirizado". Revista Estudos Feministas, Florianópolis, v. 28, n. 3, e66381, 2020.

\section{CONTRIBUIÇÃO DE AUTORIA}

Mariana Prandini Assis - concepção, discussão, condução da entrevista e redação.

Cristiano dos Santos Rodrigues - concepção, discussão e redação.

Darlane Silva Vieira Andrade - concepção, discussão e redação.

\section{FINANCIAMENTO}

Não se aplica.

\section{CONSENTIMENTO DE USO DE IMAGEM}

Não se aplica.

\section{APROVAÇÃO DE COMITÊ DE ÉTICA EM PESQUISA}

Não se aplica.

\section{CONFLITO DE INTERESSES}

Não se aplica.

LICENÇA DE USO

Este artigo está licenciado sob a Licença Creative Commons CC-BY International. Com essa licença você pode compartilhar, adaptar, criar para qualquer fim, desde que atribua a autoria da obra.

\section{HISTÓRICO}

Recebido em 21/07/2019

Aprovado em 27/02/2020

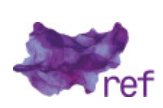

